munications will notice its shorter length, the result of restructuring at CODE. Eligibility for CODE support will be confirmed at the time a request is received.

$\begin{array}{lllll}\text { AFRICA } & \text { Botswana } & \text { The Gambia } & \text { Mali } & \text { Togo } \\ & \text { Burkina Faso } & \text { Ghana } & \text { Mozambique Uganda } \\ & \text { Burundi } & \text { Guinea } & \text { Rwanda } & \text { Zambia } \\ & \text { Cameroon } & \text { Kenya } & \text { Senegal } & \text { Zaire } \\ & \text { Chad } & \text { Lesotho } & \text { Sierra Leone } & \text { Zimbabwe } \\ & \text { Comoros } & \text { Liberia } & \text { Swaziland } & \text { Tanzania } \\ & \text { Ethiopia } & \text { Malawi } & \text { Grenada } & \text { St. Kitts, Nevis, Anguilla } \\ \text { CARIBBEAN } & \text { Antigua } & \text { Guyana } & \text { St. Lucia } \\ & \begin{array}{l}\text { Belize } \\ \text { Dominica }\end{array} & \text { Haiti } & \text { St. Vincent } \\ & \text { Papua New Guinea } & \text { Solomon Islands } & \end{array}$

\title{
THE TRAVELLING TELESCOPE
}

Dieter W. Brückner and John R. Percy

Department of Astronomy, University of Toronto, Toronto, Canada

\section{Introduction}

Astronomy is deeply rooted in the culture of almost every society, including those in the so-called "developing countries." By virtue of its fundamental applications and implications, it has had a profound influence on philosophy and on religious ritual and belief. Astronomy is vigorously pursued in the industrialized countries where, with multi-million-dollar facilities on the ground and in space, exciting discoveries in astronomy are constantly being made. In the developing countries, astronomical research and teaching activity ranges from little to none. There is tremendous potential for growth, however, especially if the industrialized countries can be persuaded to help. At any time, there are several countries which are in the process of raising their astronomy to a level at which they can become full members of the international professional astronomical community. The IAU strongly supports this process.

It would seem inappropriate to encourage developing countries to make large expenditures on astronomical research at this time, but there are many benefits to be gained from making more modest investments in astronomical research and 
education. Astronomy, with its wide popular appeal, has the potential to raise the level of scientific literacy in a society and to attract young people to a study of the sciences. In addition, and no less important, is the potential of its insights to touch those deepest human chords that transcend national boundaries and are shared by all. To paraphrase the words of Professor Mazlan Othman of Malaysia: "Astronomy is the stuff of dreams and of youthful fascination, and when you in the developed countries achieve your dreams, we hope not to be too far behind you."

\section{The History of the Travelling Telescope Project}

The concept of the travelling telescope was developed in 1984 by Derek McNally and Richard West. They were aware that, in the developing countries, astronomers had little opportunity to gain experience with modern astronomical instrumentation. Without such experience, however, they could not hope to formulate credible proposals for modern astronomical facilities in their countries. Extended visits abroad could help to alleviate the problem, but were seldom possible. If astronomers from the developing countries could not visit a telescope, then perhaps it could visit them!

One of us (JRP) became aware of the idea of the travelling telescope as a result of articles published by McNally and West in the IAU Newsletter on the Teaching of Astronomy and in the daily newspaper of the 1985 IAU General Assembly. An application was submitted on behalf of the IAU to a new grants program of the Canadian Commission for UNESCO and the Canadian International Development Agency. The application was successful; indeed, at $\mathrm{C} \$ 15,000$, it was the largest of the $\mathbf{4 0}$ grants awarded, out of more than 400 applications.

After considerable thought and consultation, we purchased the following equipment: Celestron Powerstar 0.2-m (8") telescope, Meade heavy-duty tripod and various accessories, Canon F-1 camera (old style, with mechanical shutter), Optec SSP-3 solid-state photometer with BVRI filters, Optomechanics Research Model 3C grating spectrograph, objective grating, deep-cycle 12 -volt battery with Hammond regulated power supply as charger, and several sets of star charts and books. We have constructed a set of four heavy-duty shipping cases, specially designed for the travelling telescope kit. We are also preparing instruction manuals and outlines of some possible research projects which can be carried out with the telescope. The travelling telescope was displayed at IAU Colloquium \#105 and at the 1988 IAU General Assembly, where it attracted much attention and useful advice. It will be ready for its first assignment in the summer of 1989.

\section{How the Telescope Will Be Used}

The travelling telescope will be used primarily in conjunction with two existing programs of the IAU:

International Schools for Young Astronomers. At these intensive, threeweek schools, the participants will be able to carry out useful astronomical observations with the telescope, under the guidance of the instructors. The planning, execution, reduction, and interpretation of these observations can be incorporated 
into the daytime schedule of the school. Short projects can also be carried out.

Visiting Lecturers Program. The travelling telescope will provide the host country with observational facilities over an interval of several months. Local astronomers can obtain hands-on experience with various astronomical techniques and can carry out research projects, perhaps in collaboration with one of the visiting lecturers.

By mutual agreement of the Canadian Commission for UNESCO, the University of Toronto, and the IAU, ownership of the telescope will be vested in the IAU, because of its administrative structure and its long-term commitment to improving the state of astronomy around the world. The specific assignments and itinerary of the telescope will be determined by IAU Commission 46: The Teaching of Astronomy. Countries or institutions wishing to use the travelling telescope should apply to the President of IAU Commission $46^{1}$, who will consult with the Organizing Committee of the Commission and with the co-ordinator of the travelling telescope project. If the application is approved, detailed arrangements for the shipping of the telescope will be made by the co-ordinator, in consultation with the applicant and the IAU Secretariat in Paris.

\section{Acknowledgments}

We are grateful to the UCAP Program of the Canadian Commission for UNESCO and of the Canadian International Development Agency for funding the travelling telescope project, and to the many organizations and individuals who have contributed significantly to the project in so many ways.

\section{ASTRONOMY EDUCATION: THE NEEDS OF DEVELOPING COUNTRIES}

\section{A Panel Discussion}

\section{S.E. Okoye}

Department of Physics \& Astronomy, University of Nigeria, Nsukka, Nigeria

It is perhaps somewhat ironical that although astronomy is regarded as the oldest of the sciences, yet the study of astronomy is still to be accepted. In many cases, astronomy appears to be the last of the basic sciences to be accepted as a teaching subject in the educational curricula of most of the developing countries. It is not too difficult for one to fathom the reason for this state of affairs. Taking Nigeria as a country that might be considered typical of the developing countries, one finds

\footnotetext{
${ }^{1}$ During 1986-1991 the President of IAU Commission 46 is Professor Aage Sandqvist, Stockholm Observatory, Saltsjöbaden S-13300, Sweden.
} 